\title{
O Papel da Formação de Professores no Combate ao Sexismo em Sala de Aula na Educação Infantil
}

\author{
Arilane Florentino Félix de Azevêdo \\ Tânia Maria Augusto Pereira
}

\section{SciELO Books / SciELO Livros / SciELO Libros}

AZEVÊDO, A. F. F., and PEREIRA, T. M. A. O Papel da Formação de Professores no Combate ao Sexismo em Sala de Aula na Educação Infantil. In: ARANHA, S. D. G., and SOUZA, F. M., eds. Práticas de ensino e tecnologias digitais [online]. Campina Grande: EDUEPB, 2018, pp. 363-392. Ensino e aprendizagem collection, vol. 3. ISBN: 978-85-78795-26-9. http://doi.org/10.7476/9786586221657.0013.

\section{(c) (i)}

All the contents of this work, except where otherwise noted, is licensed under a Creative Commons Attribution 4.0 International license.

Todo o conteúdo deste trabalho, exceto quando houver ressalva, é publicado sob a licença Creative Commons Atribição 4.0.

Todo el contenido de esta obra, excepto donde se indique lo contrario, está bajo licencia de la licencia Creative Commons Reconocimento 4.0. 


\title{
O PAPEL DA FORMAÇÃO DE PROFESSORES NO COMBATE AO SEXISMO EM SALA DE AULA NA EDUCAÇÃO INFANTIL
}

\author{
Arilane Florentino Félix de Azevêdo ${ }^{1}$ \\ Tânia Maria Augusto Pereira ${ }^{2}$ \\ - Pai... \\ - Hummmmm? \\ - Como é o feminino de sexo? \\ - O quê? \\ - O feminino de sexo. \\ - Não tem. \\ - Sexo não tem feminino? \\ - Não.
}

1 Mestre pelo Programa de Pós-Graduação em Formação de Professores da Universidade Estadual da Paraíba (UEPB). Pedagoga pela Universidade Federal da Paraíba (UFPB). Pesquisa sobre gênero e educação. É membro do Núcleo Interdisciplinar de Pesquisa e Ação sobre Mulher e Relações de Sexo e Gênero (NIPAM-UFPB). Atua como Tutora a Distância no Núcleo de Direitos Humanos da UFPB. E-mail: arilane_florentino@hotmail.com

2 Doutora em Linguística pela Universidade Federal da Paraíba (UFPB). Professora do Departamento de Letras e Artes e do Programa de Pós-Graduação em Formação de Professores da Universidade Estadual da Paraíba (UEPB), campus I, em Campina Grande-PB. Desenvolve e orienta pesquisas na área de Análise do Discurso, que contemplem a produção e circulação de diferentes discursos (midiático, publicitário e outros discursos do cotidiano) entrelaçados em uma rede dialógica de saber-poder, e sua influência nos saberes e práticas educacionais. E-mail: taniauepb@yahoo.com.br 
- Só tem sexo masculino?

- É. Quer dizer, não [...]

- Sexo é sempre masculino.

Extraído da crônica "Sexa" (VERISSIMO, 2001, p. 53-54)

\section{Comentários iniciais}

Vivemos em uma sociedade em que meninos e meninas, homens e mulheres compartilham de uma visão androcêntrica na qual foram educados(as) e que norteia seus pensamentos e ações. A visão sexista, de discriminação entre os sexos, é dominante em nossa sociedade e, por consequência, nas nossas escolas.

Ao chegarem à escola, as crianças já vem marcadas por diferentes fatores externos que lhes fizeram criar uma imagem de mundo, com base nos valores da sociedade androcêntrica a qual pertencem. A escola precisa intervir e não deixar seus alunos e alunas permanecerem com pensamentos tão limitados, a não intervenção seria apoiar o modelo androcêntrico socialmente divulgado. Rever velhos estereótipos e preconceitos desde a infância é a saída para um mundo mais igualitário.

Este artigo objetiva refletir sobre a construção de uma cultura sexista dentro da sala de aula na educação infantil e sobre os passos que podem ser seguidos para que se inicie um processo de desconstrução dessa cultura. Pretende contribuir para as discussões acerca do sexismo em sala de aula na educação infantil. Através de uma revisão da literatura sobre a temática abordada, buscaremos fazer uma reflexão sobre o papel que a escola cumpre na formação da consciência machista nas crianças, levando-as a se 
tornarem adultos agressores e na desconstrução do ciclo de opressão vivido pelas mulheres.

Para tanto, na primeira parte buscaremos fazer uma retrospectiva histórica do papel da mulher, desde as sociedades primitivas até a atualidade. Para isso, faremos um diálogo com Engels (2000), no que se refere à origem das relações sociais. Também faremos uma discussão sobre o sexismo e como ele se configura na educação infantil. $\mathrm{Na}$ segunda parte, discutiremos a formação docente, fazendo um recorte sobre essa formação na educação infantil. Para isso, teoricamente utilizaremos Ferreira (2014), Rocha (2012) e Oliveira (2013). Na terceira parte, refletiremos sobre o papel da formação de professores no combate ao sexismo em sala de aula da educação infantil. Por fim, faremos nossas conclusões a respeito da formação docente e a construção do sexismo em espaços educacionais tendo em vista que é necessário que os cursos de Licenciatura proponham mudanças nos currículos para que o professor da educação básica possa ter em sua formação disciplinas que abordem as questões de gênero e também, de forma transversal, a temática da sexualidade dentro das escolas.

\section{Desigualdade de gênero: um olhar pela história da mulher}

Nesta seção, buscamos trazer questões sobre a história da mulher que, muitas vezes, não são contadas. Vivemos em uma sociedade marcada por desigualdades sociais, políticas e econômicas. Nessa sociedade, busca-se fazer com que as pessoas acreditem que essas desigualdades sempre existiram e existirão, inclusive as desigualdades em torno da mulher. 
Sobre essa temática, Engels tece a seguinte reflexão:

Uma das ideias mais absurdas que nos transmitiu a filosofia do século XVIII é a de que na origem da sociedade a mulher foi escrava do homem. Entre todos os selvagens e em todas as tribos em que se encontram nas fases inferior, média e até (em parte) superior da barbárie a mulher não só é livre como, também, muito considerada (ENGELS, 2000, p. 51).

Segundo o autor, na origem da sociedade, a mulher não era explorada pelo homem, muito pelo contrário, seu papel era reconhecido dentro da sociedade. Então, como surgiu a desigualdade?

Tradicionalmente, quando uma família recebe um recém-nascido tem expectativas distintas. Se for um menino, ele é esperado com um enxoval no qual predomina a cor azul; se for uma menina, o enxoval é repleto da cor rosa. De um menino, espera-se que seja agressivo; da menina, espera-se que seja delicada. O conceito de gênero procura combater essa desigualdade pautada em aspectos biológicos para justificar diferenças.

Dentro das expectativas, os meninos são educados para serem corajosos e não terem medo de perigos, enquanto as meninas são educadas para serem delicadas e perfeitas. Espera-se que eles sejam "durões" ("menino não chora") e que elas sejam responsáveis pelo lar, pelos filhos e pelo esposo. 
Nessa perspectiva, ensina-se às crianças do sexo masculino a dominarem os sentimentos, não chorar, não demonstrar medo, porque eles serão interpretados como sinal de fraqueza e de insegurança, qualidades moralmente desqualificadas; e as do sexo feminino a serem afetuosas, solidárias, prestativas, despretensiosas, atitudes que o mundo do poder e da competição não valoriza.

Para falarmos do surgimento da desigualdade, precisamos falar primeiro do surgimento da propriedade privada. Em qualquer livro de História, ao falar do desenvolvimento das sociedades, observa-se que com esse desenvolvimento, os seres humanos vão tendo o domínio da criação do gado, da elaboração de utensílios de metais, da agricultura, entre outras. A mulher era responsável pelo trabalho doméstico e o homem pela agricultura e pelo pastoreio. O surgimento da propriedade privada vai tornar o gado e os produtos agrícolas principais fontes de riqueza da comunidade, propriedades dos homens. Sendo assim, surgiu um conflito entre a propriedade privada masculina e a organização social que tinha como base a linha matriarcal, já que nessa sociedade os homens não sabiam quais eram seus filhos legítimos, ou seja, eles não tinham como identificar seus herdeiros e, consequentemente, não tinham como garantir a sucessão de sua propriedade.

Sobre esse momento histórico, Engels considerou que, à medida que as riquezas iam aumentando, o homem adquiria uma posição mais importante do que a mulher na família e isso fazia "com que nascesse nele a ideia de valer-se desta vantagem para modificar, em proveito dos seus filhos, a ordem da herança estabelecida" (ENGELS, 2000, p. 59). 
Assim, o homem começou a querer quebrar a estrutura familiar vigente, com uma base matriarcal. A partir daí, a estrutura social passou a ter como alicerce o patriarcado. Com essa transição, a mulher passou a ser vista de outra forma dentro da sociedade. Concretizou-se o desmoronamento do direito materno e a derrota histórica do sexo feminino em todo o mundo. "O homem apoderou-se também da direção da casa; a mulher viu-se degradada, convertida em servidora, em escrava da luxúria do homem, em simples instrumento de reprodução" (ENGELS, 2000, p. 61).

Desse modo se iniciou a desigualdade social no mundo. E essa desigualdade, por sua vez, gerou vários problemas para a mulher, que passou a ser propriedade do homem. Essa reflexão nos conduz à discussão do próximo tópico sobre o sexismo.

Sexismo: conceito e origem

O sexismo se encontra presente na educação e no cotidiano através de algumas ações, seja por meio da linguagem, nos livros, nos gestos, que de maneira muito singular acabam por distanciar meninas e meninos, reforçando as diferenças e desfavorecendo a igualdade de gêneros. Os professores exercem um papel decisivo nessa questão quando colocam expectativas diferentes para meninos e meninas. Para as meninas, espera-se que elas sejam organizadas, meigas, atenciosas e comportadas. Nota-se essa situação até mesmo na linguagem usada pelos professores que tratam as meninas com meiguice e de forma mais amorosa. Já com relação aos meninos, eles serão sempre vistos como agitados, agressivos e bagunceiros. 
De acordo com Smigay (2002, p. 34), "sexismo é uma posição, ou uma postura misógena, de desprezo frente ao sexo oposto". É importante ressaltar que o sexismo pode ser exercido tanto por homens quanto por mulheres. Ainda sobre o sexismo, Smigay (2002, p. 34) apresenta a seguinte reflexão: "Inscrito numa cultura falocrática, impregna o imaginário social e o prepara a um vasto conjunto de representações socialmente partilhadas, de opiniões e de tendência a práticas que desprezam,desqualificam, desautorizam e violentam as mulheres".

Sobre a violência de gênero, Smigay $(2002$, p. 34) traz a seguinte reflexão "a violência de gênero está enraizada de forma profunda e persistente na trama social, o que a torna uma questão de difícil abordagem". De acordo com a autora, as discussões sobre violência de gênero até as décadas de 1960/1970 se inseriam apenas nos estudos sobre atitudes e opiniões. Atualmente, são incluídas nos estudos sobre gênero as categorias relacionadas ao poder.

No debate em torno da violência, especificamente contra a mulher, a autora se afasta da concepção marxista ortodoxa que atrelava a violência às questões da estrutura capitalista e traz a reflexão atrelada à cultura a qual pertencemos. Sobre isso, afirma: "Como consequência, homens seriam violentos nessa cultura, marcada pela lógica patriarcal e androcêntrica; mulheres seriam vítimas por essa mesma lógica" (SMIGAY, 2002, p. 36).

O sexismo está culturalmente presente em nossa sociedade. Se ele fosse "ensinado", direta ou indiretamente, apenas no lar e a escola fosse um espaço de desconstrução dessa cultura baseada no patriarcalismo, na qual o homem ocupa uma posição superior à mulher, acreditamos que 
existiria uma redução das cenas de violência contra a mulher exibidas atualmente na mídia em geral.

Para ilustrar nossa reflexão sobre o tema, apresentamos a charge de Armandinho (Figura 1), na qual podemos verificar que, embora sendo ainda uma criança, o menino já tem uma prática sexista com outra criança, que é uma menina, colocando-a em posição de inferioridade. As relações de gênero refletem aquilo que as pessoas interiorizaram através do que aprenderam em casa, na escola, na igreja, na sociedade em geral. Estas, quase sempre, ensinam às crianças do sexo masculino a se diferenciarem bastante das crianças do sexo feminino, do mesmo modo, a respeito daquilo que cada um é, vale e pode fazer. Isso está refletido no comportamento machista do menino na tirinha da Figura 1.
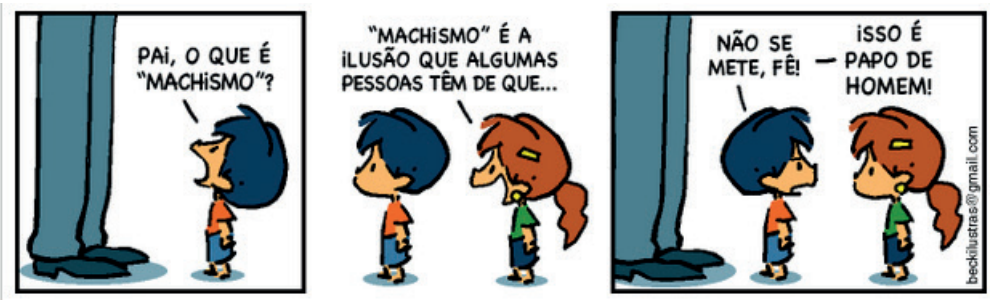

Figura 1 - O que é machismo?

Fonte: Google. Disponível em: http:/ /3.bp.blogspot.com/ C7KVEOa0JNo/VMztQ4wm1jI/AAAAAAABeA/fekkJ3KIPUk/s1600/1\%2Ba\%2B1\%2Ba\%2Ba\%2Ba\%2Ba\%2Bsexi\%2Bprinc.png

A mulher, desde a infância, é colocada "em seu lugar", ou seja, em um espaço privado. É negado a ela o direito de se expressar, de opinar, ela não deve participar de 
conversas tidas como masculinas. Sobre questões relacionadas à fala das meninas, Lakoff traz a seguinte reflexão:

Se uma menininha 'fala grosso' ou de modo rude como um menino, ela vai normalmente ser isolada, xingada ou ser motivo de gozação. Dessa forma, a sociedade, por intermédio do pai, da mãe e dos amigos de uma criança, a mantém 'na linha', em seu lugar [...]. Se a menininha aprende bem sua lição, ela não é recompensada com uma aceitação irrestrita pela sociedade; ao contrário, a aquisição desse estilo particular de fala será mais tarde uma desculpa que os outros usarão para mantê-la em uma posição inferior, para recusarem-se a levá-la a sério como ser humano. (LAKOFF, 2010, p. 15)

Na sociedade há uma exigência de um alinhamento entre gênero e sexo, suscitando nos sujeitos a necessidade de se auto afirmarem, buscando relações, ao longo da vida, que os constituam como sujeitos, numa confluência de determinantes sociais e biológicos. Essa busca é determinada pelas relações de gênero que preconizam de que maneira devem constituir-se cada sujeito, numa perspectiva machista em que homens são detentores do poder, da força e virilidade.

O machismo é uma das ideologias fundantes de diversas sociedades, relegando privilégios e poder ao homem/ macho que se sobressai, colocando a fêmea/mulher em 
um lugar de inferioridade e subalternidade. Por esse motivo, as relações entre gêneros são também compreendidas como relações de poder. Na opinião de Costa (2008, p. 22), "quando falamos em relações de gênero, estamos falando de poder. Na medida em que as relações existentes entre masculino e feminino são relações desiguais, assimétricas, mantém a mulher subjugada ao homem e ao domínio patriarca".

As relações de gênero são permeadas pela ideologia patriarcal e exercem grande influência na constituição dos sujeitos discursivos, determinam normas de conduta e estabelecem diretrizes na inter-relação entre os sujeitos. Tais relações demarcam as vozes ideológicas que cercam determinada coletividade social. Scott (1995) aponta a concepção de gênero como uma construção social articulada à noção de poder. Segundo o autor, gênero é um elemento constitutivo das relações sociais baseadas nas diferenças percebidas entre os sexos e uma forma de significar as relações de poder.

Louro (2003) também corrobora com essa discussão, afirmando que

É necessário demonstrar que não são propriamente as características sexuais, mas é a forma como essas características são representadas ou valorizadas, aquilo que se diz ou se pensa sobre elas que vai constituir, efetivamente, o que é feminino ou masculino em uma dada sociedade e em um dado momento histórico. Para que se compreenda o lugar e as relações de homens e mulheres 
numa sociedade importa observar não exatamente seus sexos, mas sim tudo o que socialmente se construiu sobre os sexos. O debate vai se constituir, então, através de uma nova linguagem, na qual gênero será um conceito fundamental (LOURO, 2003, p.21).

As relações de gênero moldam os sujeitos sociais que compõem o cenário da diversidade sexual e são categorias de análise que devem ser levadas aos diversos espaços públicos a fim de fomentar discussões e debates a respeito. A Escola é o lugar de estabelecimento de uma retórica que seja pensada a partir da própria diversidade, repleta de nuances e classificações que devem acompanhar fatos, cotidianos, aspectos socioculturais e a vivência de alunos e alunas das redes públicas e privadas.

Como afirma Saffioti (2004, p. 136), o gênero não é um conceito neutro. Pelo contrário, "carrega uma dose apreciável de ideologia" direcionando, assim, as formas de interação social. A célebre frase "Não se nasce mulher, torna-se mulher", de Beauvoir (1980), elucida a ideia do gênero como uma identidade construída a partir das relações entre sujeitos, localizados em um tempo e espaço bem definidos.

No interior dessas relações são evidentes, em um contexto essencialmente patriarcal, papéis preestabelecidos destinados ao homem e à mulher. Ao desempenhar estes papéis, a mulher aprende a ser mulher, bem como o homem aprende a ser homem. São figuras estereotipadas determinadas por fatores sociais, ideológicos e discursivos: homem não chora, fala grosso, impõe sua masculinidade 
através da força; a mulher, por sua vez, deve ser delicada, sensível e apta às atividades domésticas.

Todas essas questões observadas na sociedade se refletem na sala de aula. No próximo tópico, discutiremos como esse sexismo é construído na educação infantil.

\section{O sexismo na educação infantil}

O sentimento de infância surgiu na Modernidade. As sociedades antigas e medievais enxergavam as crianças como adultos em miniatura. Esse novo entendimento a respeito da criança repercutiu profundamente na Pedagogia. (DANELON, 2015). Consequentemente, a educação passou a se ocupar da construção da subjetividade da criança moderna. Sobre isso, Resende (2015) afirma que:

A partir do momento em que a infância é inventada pela Modernidade fazendo-a ocupar esse espaço como sujeito-objeto, a educação passa a ser um imperativo, o que leva, também, à invenção da pedagogia moderna, como um campo científico e como política de conhecimento, constituindo-se de discursos voltados para o estudo e a acumulação de saberes sobre a criança e seu corpo, seu desenvolvimento, suas capacidades, suas vontades, suas tendências, suas brincadeiras, suas potencialidades, suas fragilidades, suas vulnerabilidades, seus instintos, suas paixões e potências que, por sua vez, se acoplam a práticas discursivas e não discursivas em que tais sabres se imbricam em mecanismos de poder, cujo resultado será a produção de uma criança específica, a produção da subjetividade infantil moderna (RESENDE, 2015, p. 129-130). 
Com o surgimento da Modernidade, outro olhar foi dado à criança, com isso a Pedagogia teve de ser reinventada para se adequar as necessidades dessa nova sociedade.

Aires (1981, p. 29) corrobora o surgimento desse sentimento de infância e complementa essa reflexão ao falar sobre as idades e suas funções sociais. "Primeiro, a idade dos brinquedos: as crianças brincam com um cavalo de pau, uma boneca, um pequeno moinho ou pássaros amarrados". O autor também reflete sobre a criança e a instituição educacional "depois, a idade da escola: os meninos aprendem a ler ou seguram um livro e um estojo; as meninas aprendem a fiar" (AIRES 1981, p. 29). A escola conduzia "destino" para as crianças de acordo com o sexo.

A Pedagogia passou a estudar o comportamento infantil, entender suas necessidades e capacidades para, através desse conhecimento, saber como melhor governar as crianças.

Segundo as Diretrizes Curriculares Nacionais para Educação Infantil, criança é:

Sujeito histórico e de direitos que, nas interações, relações e práticas cotidianas que vivencia, constrói sua identidade pessoal e coletiva, brinca, imagina, fantasia, deseja, aprende, observa, experimenta, narra, questiona e constrói sentido sobre a natureza e a sociedade, produzindo cultura (DCNEI, 2010, p. 12). 
O conceito que as Diretrizes trazem sobre criança faz com que reflitamos, principalmente, sobre: a) construção da identidade pessoal e coletiva e, b) a construção do sentido sobre a natureza e a sociedade, produzindo cultura. Ou seja, é ingênuo acreditar que a criança não constrói aquilo que vivencia.

As crianças observam em casa as relações entre os pais. Se esse pai grita com a mãe, bate na mãe, o menino aprende que tem poder sobre a mulher e a menina aprende que tem que ser submissa aos homens. Ou seja, se essas ou outras violências simbólicas são construídas dentro de casa, as crianças estão propensas a reproduzir essa cultura quando adultos.

A escola, então, seria o espaço para desconstruir essa cultura vigente. Entretanto, quando chegamos às salas de aula da educação infantil, encontramos brinquedos destinados a meninos e a meninas. Para as meninas, os brinquedos referentes ao lar, como se o destino da mulher fosse ser mãe e dona de casa. Para os meninos, aviões, carros, caixa de ferramentas, ou seja, no futuro o menino poderá ser o que quiser.

Finco (2003), ao observar as brincadeiras entre meninos e meninas em uma escola de crianças de 0 a 6 anos, verificou que o sexismo existente no mundo adulto vai se construindo dentro da escola ao longo dos anos, pois nessa primeira fase as crianças ainda brincam com os brinquedos livremente, sem se preocupar se é de menino ou de menina. A autora afirma que "esses meninos e meninas ainda não possuem o sexismo da forma como ele está disseminado na cultura construída pelo adulto: as crianças vão aprendendo a oposição e a hierarquia dos sexos 
ao longo do tempo que permanecem na escola" (FINCO 2003, p. 95).

Ainda de acordo com a autora, as escolas possuem mecanismos, mesmo que sutis, que constroem as diferenças de gênero entre meninos e meninas, e essa construção pode resultar na formação de homens e mulheres que buscam atender as relações que a sociedade estabelece, ou seja, os primeiros como fortes e capazes de tudo e as mulheres submissas, onde acreditam que é seu dever assumir todas as responsabilidades do lar, mesmo trabalhando fora de casa também. "Muitas pesquisas apontam que a escola possui mecanismos sutis que constroem e mantêm as diferenças entre os sexos" (FINCO, 2003, p. 93).

Esses são pequenos exemplos que deixam no subconsciente dos sujeitos envolvidos as marcas de uma cultura construída em cima do sexismo e da violência doméstica. Defendemos que a formação docente pode contribuir para a desconstrução dessa cultura sexista.

\section{Formação de professores: uma retrospectiva histórica até a atualidade}

Para se ter uma melhor compreensão em torno da formação de professores em nosso país, se faz necessário fazer uma retrospectiva pela história da educação brasileira. É justamente isso que Oliveira (2013) apresenta. Em um primeiro momento, logo após o "descobrimento" do Brasil, foram os Jesuítas os principais, para não dizer os únicos, que tomaram para si a responsabilidade com a educação da nova colônia portuguesa.

No ano de 1549, mesmo existindo uma grande preocupação com a catequese indígena, o processo de educação 
formal aqui existente era voltado para a elite. Sendo assim, a formação de professores era organizada a partir dessa perspectiva. Esse era o único sistema educacional brasileiro e perdurou até o ano de 1759, quando os jesuítas foram expulsos da nossa terra pelo Marquês de Pombal (OLIVEIRA, 2013).

A nova administração mudou a forma como o ensino era organizado. Começou um sistema intitulado "aulas régias". Era um ensino destinado a nobreza. Porém, diferente do ensino jesuíta, esse era fragmentado e sem objetivos claros. Essa forma de ensino perdurou mesmo após a Proclamação da Independência do Brasil. Em 1834, a responsabilidade do ensino e da formação de professores ficaram a cargo do governo das províncias. O ensino continuou sendo ministrado por professores "leigos", sem formação específica para ministrar os conteúdos das diversas disciplinas.

Em 1835, começam a surgir as Escolas Normais, que tinham por objetivo formar professores para o ensino primário. Nessas escolas faltavam verbas e professores preparados, didaticamente, para cumprir a função de formar novos professores para o ensino primário de nosso país. Mas, é inegável o avanço que se teve com a criação dessas escolas.

Na retrospectiva feita por Oliveira (2013), recebe destaque a criação do Pedagogium, primeiro Centro de Estudos Pedagógicos em nível Superior, em 1890. Esse Centro teve uma duração rápida e não conseguiu se consolidar. Nesse momento, o poder público não se responsabilizou pela educação superior e quem assumiu esse papel foi assumido por instituições religiosas de iniciativa privada que estavam organizadas aqui no Brasil. 
Em 1901, foi criado o primeiro instituto de educação em nível superior. Vários avanços podem ser vistos nessa época, pois o poder público passou a se preocupar e investir na formação de professores. Na década de 1970, os cursos de pós- graduação começaram a impulsionar as pesquisas em torno da educação. Até então, a formação de professores tinha um caráter tecnicista.

Em 1996, pode-se observar na LDB que a formação de professores tem que atender a três aspectos essenciais, dentre eles, a associação da teoria com a prática. Nesse ponto, Ferreira (2014) debate a complexa relação entre teoria e prática pedagógica. Sobre teoria, podemos entender como um "conjunto de regras ou leis, mais ou menos sistematizadas, aplicadas a uma área específica" (HOUAISS, 2014). No que diz respeito à prática, podemos entender como "ação, ato ou efeito de fazer (algo)". O século passado ainda manteve a tendência do século XIX, influenciado pelo método cartesiano, que via uma maior eficácia na divisão do conhecimento em campos especializados.

Esse pensamento afeta diretamente todas as áreas do conhecimento, inclusive a educação. Instala-se uma cisão entre teoria e prática, criando uma dicotomia entre professor e pesquisador. Substituir a teoria cartesiana por uma teoria da complexidade (teoria holística) é uma necessidade a ser alcançada no século XXI.

Ferreira (2014) aponta a práxis como método para romper com a cisão entre teoria e prática. Sobre práxis, entendemos "a atitude (teórico-prática) humana de transformação da natureza e da sociedade" (FERREIRA 2014, p. 35, apud PIMENTA, 2009, p.86) 
A formação docente para educação infantil:

desafios e particularidades

A retrospectiva histórica da formação docente mostra um pouco dos avanços e retrocessos que tivemos em torno dessa temática. Nesse tópico, abordaremos a formação docente, especificamente para educação infantil.

Em um primeiro momento, situaremos o local de atuação e os sujeitos envolvidos diretamente com esse profissional. De acordo com as Diretrizes Curriculares Nacionais para Educação Infantil, as creches e/ ou pré-escolas foram atendidas como direito social das crianças através da Constituição de 1988, que fala do dever do Estado para com a Educação. Sendo assim, começou a existir uma mudança de concepção em torno dos locais onde as crianças eram deixadas quando as mães iam trabalhar. Sobre essa mudança, as Diretrizes apresentam o seguinte:

Desde então, o campo da educação infantil vive um intenso processo de revisão de concepção sobre educação de crianças em espaços coletivos, e de seleção e fortalecimento de práticas pedagógicas mediadoras de aprendizagens e do desenvolvimento das crianças (DCNEI, 2010, p. 7).

Houve uma mudança de concepção em torno dos locais destinados a crianças de 0 a 5 anos. Também é exigida uma mudança no profissional que atua nessas instituições. A LDB 9.394/96, em seu artigo 62, fala da necessidade de termos um profissional formado em nível superior para 
atuar na educação básica, ou no mínimo, que tenha uma formação de nível médio, na modalidade normal.

Rocha (2012) faz uma reflexão sobre a relação das crianças com a educação que elas recebem. Na visão da autora, o aluno inicia a fase estudantil na primeira infância aprendendo conteúdos práticos que facilitarão, posteriormente, seu período de alfabetização e toda a vida acadêmica, e que serão essenciais para sua vida adulta.

A formação do docente para atuar com criança, mais do que em qualquer outra faixa etária, precisa estar direcionada com questões ligadas à formação de um sujeito que se desenvolva livre de preconceitos (seja de gênero, de classes sociais, de etnias), pois, é nessa fase que as crianças vão construindo internamente os valores sociais que irão levar para a vida adulta.

Finco (2003) destaca o papel do educador da educação infantil como fundamental na desconstrução da cultura sexista existente no mundo adulto. E para que esse papel seja cumprido de forma exitosa, faz-se necessário uma formação que abarque todas as questões relacionadas ao gênero e sua construção dentro das escolas. Sobre isso, a autora afirma que: "deste modo, o profissional de educação infantil tem papel fundamental para que essas relações possam acontecer de forma livre, sem cobranças quanto a um papel sexual pré-determinado" (FINCO, 2003, p. 95).

Sobre a formação permanente dos docentes que trabalham na Educação Infantil, Rocha (2012, p. 31) comenta que "somente aprofundando-se nos estudos para a compreensão do desenvolvimento humano, o professor poderá desenvolver seu trabalho com a qualidade que a Educação Infantil necessita". 


\section{Formação de professores $\mathrm{x}$ sexismo}

Uma formação docente adequada para combater o sexismo se faz necessário. Estamos inseridos em uma cultura baseada no preconceito, principalmente relacionado às mulheres, ou ao que se considera feminino. É necessário que tenhamos a compreensão de que as nossas ações em sala de aula legitimam ou não essa cultura. Devemos educar as crianças para abolirem o ciclo do machismo, agindo com atitudes que destruam sua perpetuação.

Finco (2003) alerta sobre o papel do educador na reafirmação ou desconstrução dessa sociedade sexista. Se esse profissional não reflete sobre suas atitudes em sala de aula, ele pode estar contribuindo para a cristalização de concepções sexistas na cabeça das crianças. Nas palavras da pesquisadora,

quando a professora não reflete sobre sua influência nas relações dos meninos e meninas, ela pode organizar a brincadeira de uma forma a favorecer o sexismo, a prática da professora pode fazer com que as crianças se organizem em grupos distintos de meninas e meninos, sem que haja uma ordem explícita para isso (FINCO, 2003, p. 98).

É importante entendermos que fomos educados sob uma cultura sexista, onde as brincadeiras de meninos e meninas eram separadas. Perdi as contas de quantas vezes sai escondida para jogar bola com meu irmão e com pouco tempo ouvia a voz da minha mãe "entra menina, vá 
brincar de boneca com sua irmã, ta vendo que não dá certo você brincar lá fora misturada com os meninos" (Arilane). Isso sempre criou em mim a visão de que o homem era livre e às mulheres cabia o espaço privado do lar.

Essa situação acontece até hoje e dentro das escolas também. Muitas vezes as professoras mandam os meninos para o pátio para jogar bola e deixa as meninas na sala brincando de casinha. Sendo assim, como disse Finco (2003), se nós educadores não fizermos um trabalho de reflexão em torno das nossas próprias atitudes iremos está contribuindo direta ou indiretamente com a reafirmação da sociedade sexista, pois atitudes como essas, citadas acima, contribuem para uma compreensão de que o lugar da mulher é sempre privado, seja dentro de casa, de uma sala; já os meninos são livres para irem aonde quiser.

Sobre o enraizamento da cultura sexista, Louro (2000) afirma que

Em nossa sociedade, a norma que se estabelece, historicamente, remete ao homem branco, heterossexual, de classe média urbana e cristão e essa passa a ser a referência que não precisa mais ser nomeada. Serão os 'outros' sujeitos sociais que se tornarão 'marcados', que se definirão e serão denominados a partir dessa referência. Desta forma, a mulher é representada como 'o segundo sexo' e gays e lésbicas são descritos como desviantes da norma heterossexual (LOURO, 2000, p. 9). 
Como foi dito anteriormente, os professores, estão imersos em uma cultura preconceituosa. Não é a toa que a escola, historicamente, tem cumprido o papel de reafirmar as desigualdades. Acerca dessa construção da escola, Louro (2000, p. 11) pondera que "o investimento mais profundo, contudo, o investimento de base da escolarização se dirigia para o que era substantivo: para a formação de homens e mulheres "de verdade".

Devemos começar um processo de desconstrução dessa concepção de sociedade patriarcal, falocrática e sexista que está posta. Para Finco (2003, p. 99), “a proposta da desconstrução das dicotomias significa problematizar a constituição de cada pólo, demonstrar que cada um, na verdade, supõe e contém o outro; mostrar que cada pólo não é único, mas plural".

A autora defende a necessidade de uma desconstrução dessa cultura de gêneros em que estamos submersos e que é refletida na escola. Principalmente, no que diz respeito a como as crianças entendem as relações de gênero que são postas no seu dia a dia. Tais relações foram construídas historicamente em pólos distintos. "A desconstrução dos pólos masculinos e femininos traz uma proposta de reflexão e nos aproxima das formas como as crianças se relacionam frente às diferenças de gênero na infância" (FINCO, 2003, p. 99).

Louro (2003) sustenta a ideia de que gênero é uma construção social, que está intrinsecamente relacionado aquilo que a sociedade considera como o papel social/ cultural mais adequado para homens e mulheres e está relacionado às noções construídas de masculinidade $\mathrm{e}$ feminilidade. 
Uma formação docente baseada em uma concepção mais holística, que enxerga o ser humano em todos os seus aspectos, na sua complexidade, faz com que comecemos a desconstruir o ciclo do sexismo dentro das salas de aula da educação infantil. Para que isso se concretize, é necessário fazer uma reflexão sobre o currículo escolar e o sexismo.

No que diz respeito ao ensino nos cursos de formação de professores, Altman (2013) comenta sobre alguns motivos que levam as universidades a não terem nos currículos de licenciaturas disciplinas ligadas às questões de gênero, sexualidade e diversidade sexual. Segundo a autora, os cursos de graduação quase não contemplam esses temas, devido a vários aspectos.

Sem ter a pretensão de abordá-los na sua plenitude, gostaria de me referir a alguns deles. Diferentemente do ensino escolar, as universidades são dotadas de maior autonomia, inclusive no que se refere ao conhecimento. A autonomia universitária propicia tanto a inclusão quanto a ausência desses temas nos seus currículos (ALTMAN, 2013, p. 79).

Um dos aspectos apontados é a autonomia que as Universidades possuem para elaborarem seus currículos. Sendo assim, dependendo da linha de pesquisa em que os professores dos cursos de licenciatura estejam inseridos, as graduações não ofertam disciplinas que debatam a questão de gênero com os futuros educadores da escola 
básica. São esses educadores que ao chegarem às escolas contribuirão com o debate em torno do Projeto Político Pedagógico, são esses professores que escolherão o livro didático a ser trabalhado na escola. Enfim, se esses profissionais não tiverem uma formação adequada em torno da questão de gênero, a tendência é negligenciar essa discussão na educação básica e reforçar cada vez mais o sexismo entre as crianças.

Ribeiro e Silva comentam que o currículo escolar

parece ignorar os/as alunos/as como sujeitos sociais e históricos, constituídos/as dentro de determinada cultura, preocupando-se apenas em instituir padrões, normas, habilidades, valores e outros condicionantes; o currículo escolar acredita que de fato esteja efetivando a formação de bons cidadãos (RIBEIRO e SILVA, 2011, p. 525).

Não ter um currículo que problematize as questões de gênero fará com que acreditemos que estamos construindo bons cidadãos para a sociedade sem se preocupar em que tipo de cidadão, de fato, queremos para a sociedade. Será que a boa cidadã é que aquela que senta de perna cruzada, que fala baixo, que não reage? Será que o bom cidadão é aquele que entende ser livre para fazer o que quiser, ou seja, explorar mãe e mulher dentro de casa sem contribuir com as atividades domésticas? Enfim, temos que ter cuidado em não estarmos apenas reproduzindo os "bons cidadãos" que já temos. 
Como já foi dito, a falta de um currículo que contemple as discussões de gênero dentro das universidades reflete na ausência dessa discussão dentro da escola.

Outra questão importante apontada por Altman (2013) diz respeito ao atendimento da demanda social e histórica que as escolas procuram contemplar em seus currículos no que diz respeito à educação sexual. Sobre isso, a autora afirma que "as intervenções sobre a sexualidade na escola passaram por diferentes focos de atenção, como o onanismo, as DSTs, a Aids, a chamada gravidez na adolescência e agora o respeito à diversidade sexual" (ALTMAN, 2013, p. 73).

A autora aponta o percurso das discussões em torno da sexualidade dentro da escola e só que recentemente se começou a discutir sexualidade no âmbito da diversidade sexual, com a inclusão de debates em torno do respeito, entre outras questões ligadas a heterogeneidade.

Amado (2010) traz uma reflexão importante acerca da mudança de concepções em torno do currículo nos cursos de formação de professores,

[...] nos tempos atuais, o currículo deve buscar entendimentos e práticas em pequenos marcadores sociais, suas chamadas minorias, diferenças, que abrem a agenda educacional para questões de gênero, escolhas sexuais, multiculturalismo, religiosidade, força da mídia e dos artefatos culturais, políticas de identidade, racismo, etnocentrismo e etc (AMADO, 2010, p. 5). 
Como já foi dito por Altman (2013) as questões curriculares que discutem a sexualidade como um todo vão tentar contemplar as demandas históricas de cada época. Podemos observar na mídia e em outros espaços que a sociedade vem mudando, casamento homossexual sendo permitido por lei, o empoderamento feminino através de diversos movimentos, como por exemplo "A Marcha das Vadias", ou seja, a escola precisa trazer esse debate para dentro das salas de aula. Modificar o currículo para que esse debate seja contemplado é umas das principais pautas da atualidade. Pois, só educando esses novos sujeitos para uma sociedade aberta a diversidade é que vamos começar a desconstruir à violência que está posta para as minorias.

\section{Comentários finais}

A história da desigualdade, principalmente a de gênero, é datada de muitos séculos, desde o surgimento da propriedade privada nas sociedades primitivas. A partir daí, foi sendo construída uma cultura baseada no sexismo e em violências de todo tipo contra a mulher. Percebemos também que a escola vem cumprindo um papel de reafirmar essa cultura.

Para que a escola comece a desconstruir esse processo, algumas questões precisam ser observadas. Em primeiro lugar, no que diz respeito à formação docente. De nada adianta quebrar o ciclo do machismo dentro da escola se não temos professores capacitados para isso. Sendo assim, os cursos de Licenciatura devem ampliar as disciplinas relacionadas às questões de gênero. Em um segundo momento, os professores da educação infantil precisam 
entender que suas atitudes em sala de aula contribuem, direta ou indiretamente, com a formação do sujeito. E por fim, é preciso, de forma transversal, trabalhar a sexualidade dentro da escola, iniciando na educação infantil.

A escola não apenas transmite conhecimento, ela também fabrica sujeitos, produz identidades étnicas, de gênero, de classe. Reconhecemos que essas identidades estão sendo produzidas através de relações de desigualdade. Romper com os modelos hegemônicos não é uma tarefa fácil. A prática predominante na educação infantil ainda possui a forte influência da formação para o ensino tradicional, onde há o predomínio do binômio masculino/feminino. Não podemos deixar que esse predomínio ofusque outros caminhos. Aspiramos uma educação em que os meninos e meninas não sejam ensinados a gostarem de coisas diferentes, a fazerem coisas diferentes, a serem hábeis em funções ou tarefas distintas.

Orientar a educação sexual infantil requer uma consolidação de competências didáticas, debates constantes, desmistificação de discriminações, preconceitos, estereótipos e "padrões sexuais", construir a disseminação do respeito entre os alunos e professores assim como entre alunos e alunas.

Devemos olhar a educação infantil para além das diferenças, pois é nesse espaço que se inicia a luta para uma educação não sexista e nessa batalha os professores desempenham um papel relevante, é a partir de suas práticas que estereótipos podem ser quebrados. A escola é um ambiente de extrema importância para o desenvolvimento de meninas e meninos, e neste espaço as crianças devem se relacionar livremente, independente de gênero. 
Defendemos que é possível uma educação igualitária para meninas e meninos.

Acreditamos que só uma formação docente baseada na construção de uma sociedade mais justa e livre de preconceito poderá educar crianças capazes de desconstruir a cultura vigente, formando adultos que não tenham discriminação de gênero, classes sociais, etnias etc.

\section{Referências}

ALTMAN, Helena. Diversidade sexual e educação: desafios para a formação docente. Revista Latino Americana Sexualidad, Salud y Sociedad. Campina-SP, 2013, p. 69-82.

AMADO, Paula Barreto Doria. Relações de "Poder e Saber" no currículo: enquanto formação, controle e disciplina do corpo na escola. GT8. Espaços Educativos, Currículo e Formação Docente. Tiradentes/SE. 2010, p. $1-10$.

BEAUVOIR, Simone. O Segundo sexo - a experiência vivida. Tradução de Sérgio Millet. 4. ed. São Paulo: Difusão Européia do Livro, 1980.

BRASIL. Ministério da Educação. Secretaria de Educação Básica. Diretrizes curriculares nacionais para a educação infantil /Secretaria de Educação Básica. Brasília: MEC, SEB, 2010.

COSTA, Ana Alice. Gênero, poder e empoderamento das mulheres. 2008. Disponível em: http://www. 
adolescencia.org.br/empower/website/2008/imagens/textos_ pdf/Empoderamento.pdf. Acesso em: 26/11/2013.

Dicionário Houaiss On-line Beta da Língua Portuguesa. Disponível em: http://houaiss.uol.com.br. Acesso em: 30/05/2016

ENGELS, Friedrich. A origem da família, da propriedade privada e do Estado. 15. ed. Rio de Janeiro: Bertrand Brasil, 2000

FERREIRA, Jacques de Lima. A complexa relação entre teoria e prática pedagógica na formação de professores. Petrópolis, RJ: Vozes, 2014.

FINCO, Daniela. Relações de gênero nas brincadeiras de meninos e meninas na educação infantil. Revista Proposições. v.14. n 3. set/ dez. p. 89-101. São Paulo, 2003.

LAKOFF, Robin. Linguagem e lugar da mulher. In:

FONTANA, Beatriz; OSTERMANN, Ana Cristina (Orgs.). Linguagem, gênero e sexualidade. São Paulo: Párabola, 2010, p.15.

LOURO, Guacira Lopes Gênero, sexualidade e educação: uma perspectiva pós-estruturalista. 6. ed. Petrópolis, RJ: Vozes, 2003.

LOURO, Guacira Lopes (Org.). O corpo educado: pedagogias da sexualidade. Belo Horizonte: Autêntica, 2000. 
OLIVEIRA, Maria Marly de. Formação de Professores: produção de conhecimento - sequência didática. Petrópolis, RJ: Vozes, 2013.

PIMENTA, S. G. O estágio na formação de professores: unidade teoria e prática. 8. ed. São Paulo: Cortez, 2009.

RIBEIRO, Paula Regina Costa. SILVA, Benícia O. da. Sexualidade na sala de aula: tecendo aprendizagens a partir de um artefato pedagógico. Estudos Feministas. Florianópolis, 2011, p. 521-533.

ROCHA, Luciana Caprice Silva Santos da. Formação de professores na educação infantil. Revista Projeção e Docência. v.3. n.1. 2012, p.35.

SAFFIOTI, Heleieth I. B. Gênero, patriarcado, violência. São Paulo: Fundação Perseu Abramo, 2004.

SCOTT, Joan W. Gênero: uma categoria útil de análise histórica. Educação \& Realidade. Porto Alegre. v. 2, n. 20, p. 71-99, jul/dez., 1995.

SMIGAY, Karin Ellen Von. Sexismo, homofobia e outras expressões correlatas de violência: desafios para a psicologia política. Psicologia em Revista. v. 8. n. 11. Belo Horizonte, 2002, p. 32-46.

VERÍSSIMO, Luis Fernando. Sexa. In: Comédias para se ler na escola. Rio de Janeiro: Objetiva, 2001, p. 53-54. 